\title{
Evaluation of a web-based registry of inherited bleeding disorders: a descriptive study of the Brazilian experience with HEMOVIDAweb Coagulopatias
}

Suely Meireles Rezende ${ }^{1,2^{*}}$, Silvia Helena Lacerda Rodrigues², Kelly Neves Pinheiro Brito², Diego Lima Quintino da Silva², Marcos Lázaro Santo ${ }^{3}$, Bárbara de Jesus Simões², Guilherme Genovez ${ }^{4}$ Helder Teixeira Melo², João Paulo Baccara Araújo², Danila Augusta Accioly Varella Barca ${ }^{5}$ and on behalf of the HEMOVIDAweb Coagulopatias Study Group

\begin{abstract}
Background: Inherited bleeding disorders (IBD) consist of a group of rare heterogeneous diseases, which require treatment for life. Management of these disorders is complex and costly. Therefore, good quality data of the affected population is crucial to guide policy planning. The aim of this manuscript is to describe the impact of a national, web-based registry - the Hemovidaweb Coagulopatias (HWC) - in the management of the IBD in Brazil.

Methods: The system was developed in PHP 5.0 language and is available on the internet at http://coagulopatiasweb. datasus.gov.br. The system was validated in September 2008 and launched nationally with input from January 1, 2009. HWC collects variables related to socio-demographic, clinical, laboratory and treatment data of patients with IBD.

Results: Within 7 years, there was an increment of $90.8 \%$ on the diagnosis of IBD altogether, which increased from 11,040 in December 2007 to 21,066 in December 2014. This is now the fourth and third largest world population of patients with haemophilia and von Willebrand's disease (VWD), respectively, according to the most recent (2015) Annual Global Survey of the World Federation of Hemophilia. The data collected provided the basis for planning and implementing home therapy, prophylaxis and immune tolerance induction (ITI), recently initiated in Brazil.

Conclusion: HWC was an effective tool in the increment of registration of patients with IBD in Brazil. Furthermore, it was essential to support policy planning, monitoring, evaluation and treatment. Future development should focus on surveillance, health outcomes and research. Every country should implement a national registry on IBD.
\end{abstract}

Keywords: Bleeding, Haemophilia, von Willebrand disease, Registry, Brazil, Factor VIII, Factor IX

\section{Background}

Inherited bleeding disorders (IBD) are heterogeneous group of rare diseases characterized by bleeding manifestations of variable severity. IBD require treatment for life, which is complex and costly. In most of the cases,

\footnotetext{
*Correspondence: srezende@medicina.ufmg.br; suely.rezende@uol.com.br 'Department of Internal Medicine, Faculty of Medicine, Universidade Federal de Minas Gerais, Avenida Alfredo Balena, 190 - 2nd floor- room 243, Belo Horizonte, Minas Gerais ZIP 30130-110, Brazil

${ }^{2}$ Coordenação Geral de Sangue e Hemoderivados, Ministry of Health, SAF Sul, Edifício Premium, Torre II, room 202, CEP:70070-600 Brasília, Distrito Federal, Brazil

Full list of author information is available at the end of the article
}

treatment requires intravenous infusion of factor concentrates (FC) and/or blood products at prophylactic and/or episodic basis.

Clinical registries have a wide application in the management of IBD. Increasingly, national registries are providing patients, clinicians and governments an insight into the needs of patients, an important tool to guide health policies. Keeping updated registries is important for planning care, monitoring the effective use of resources, health outcomes and implementing surveillance [1]. Registries are particularly important for Government planning when a substantial amount of public resource 
is spent on groups of rare diseases, such as it is the case of the IBD.

Within the last years, there has been a substantial progress on the implementation of registries devoted to IBD in many countries [2-10]. However, many countries still do not have a national registry devoted to IBD [11] nor provide registry with good quality data [12]. In Brazil, until December 2008, the registration of patients with IBD was performed manually using spreadsheets, which had several limitations, such as difficulty in updating information, typing errors, duplications, and others. By noticing the need to improve data collection, the Ministry of Health $(\mathrm{MoH})$, set up a modern, easily accessible web-based national registry of patients with IBD, the HEMOVIDAWeb Coagulopatias (HWC).

This report aims at describing the development and impact of HWC on registration, diagnosis and management of IBD in Brazil. To our concern this is the first report which shows an impact of a national web-based registry in comparison with a previous manuallycollected registry.

\section{Methods}

\section{Study}

This is a descriptive study aimed at reporting the impact of a web-based registry of IBD in comparison with previous data manually-collected in Excel spread sheets [6]. Patients' data were entered by health professionals working in the haemophilia treatment centers (HTCs).

\section{The program of IBD in Brazil}

The $\mathrm{MoH}$ manages the Program of IBD in Brazil. The main roles of the Program are: (i) purchase of FC and distribution to HTCs, (ii) promotion of education of multiprofessional teams dealing with IBD, (iii) organization of guidances on management of IBD and (iv) provision of an updated registry.

The management and treatment of patients with IBD are guaranteed by the Brazilian Public National Health System - named Sistema Único de Saúde (SUS). Most patients with IBD are attended in HTCs located in the 26 Brazilian States and 1 Federal District. Patients who have private health insurance and milder forms of IBD are likely to be attended at private clinics. However, due to the fact that approximately $100 \%$ of FC purchased in Brazil is acquired centrally by the $\mathrm{MoH}$, patients who demand treatment are attended at the HTCs. Therefore, it is reasonable to assume that approximately $100 \%$ of patients with moderate/severe forms of IBD are treated in the public sector (HTCs). For this, it is required that all patients are registered with a HTC in order to receive treatment.

\section{The HEMOVIDAWeb Coagulopatias system}

The development of HWC started in early 2008 and was implemented from January 2009. Its development and management is funded by the $\mathrm{MoH}$. It was triggered by the need of developing a national registry capable of collecting reliable clinical data of patients with IBD in the country and monitoring FC use.

The system was developed in PHP 5.0 language and is available on the internet at http://coagulopatiasweb.data sus.gov.br. The access to the system can be reached by using Internet Explorer 7, Mozilla Firefox or Google Chrome. The system was validated in September 2008 followed by a national training course for users in November 2008. It was then launched nationally with input from January 1, 2009.

The system was conceived by the creation of administrative modules assessed by individual username and password. Users signed a consent form which stated their responsibility to confidentiality and appropriate use of the system and data. The system contains six structured access profiles, classified as (i) Federal (MoH) Manager, (ii) State Manager, (iii) Care Provider, (iv) Service Provider, (v) Assistance Provider and (vi) Distribution Controller. Professionals in charge of these accesses are mainly haemophilia nurses, haemophilia doctors and pharmacists. The States are the responsible bodies for the provision of access profiles from ii to iv, in a decentralized flow under their decision.

\section{Modules}

The modules were composed by two major groups: administrative and clinical. The administrative module was composed by: (i) registration, designed for registration of a new cases of IBD or transfer of a registered patient to another state; (ii) data extraction; (iii) emission of reports and (iv) stock control, use and distribution of FC.

The clinical module included: (i) socio-demographic data, (ii) diagnosis, (iii) clinical complications, (iv) laboratory tests and (v) treatment.

\section{Variables collected in the clinical module}

Socio-demographic variables included: name, date of birth, sex, age, race, education, marital status, occupation, weight, height and body mass index.

The list of diagnosis comprised: HA or HB (if severe, moderate, mild or unknown), classification according to [13]; von Willebrand's disease (vWD) (if types 1, 2A, 2B, $2 \mathrm{~N}, 2 \mathrm{M}, 3$, platelet type or unknown); afibrinogenaemia, hypofibrinogenaemia, dysfibrinogenemia, deficiencies of factors II, V, VII, X, XI, XII, XIII, high molecular weight kininogen, prekallikrein, PAI-1, combined deficiencies, deficiency of vitamin K-dependent factors, acquired inhibitors, Bernard-Soulier syndrome, Glanzmann's 
thrombasthenia, other platelet disorders and other undiagnosed bleeding conditions. Variables on complications include: muscle skeletal complications; use of catheter; inhibitor status (screening and titration) and death (with causes).

Laboratory tests include: $\mathrm{ABO}$ blood group and $\mathrm{Rh}$ status; vaccination status for hepatitis $\mathrm{A}$ and $\mathrm{B}$; serological tests for human immunodeficiency virus (HIV), human T lymphotropic virus (HTLV), hepatitis B and C. Whether any of these diseases are confirmed, we collect information regarding treatment.

Finally, in the treatment module, we collect: use of FC by type, data of infusion and quantity (in international units [IU] or other unit), lot, motive of use (surgery, trauma, bleeding, type of bleeding) and category of use (if home treatment, prophylaxis, episodic, hospital use, immune tolerance induction [ITI]). This module includes a tool for stock control, use and distribution of FC which is linked to $\mathrm{MoH}$ stock system.

\section{Results}

The impact of the system on the registration of patients and on the prevalence of IBD

In the first months after the implementation of the system, the number of registered patients with all forms of IBD increased $30.8 \%$ rising from 11,040 patients in December 2007 when the registrations were still performed in Excel spreadsheets to 14,436 patients in December 2009, the first year of use of HWC (Fig. 1). After 7 years, there was an increment of $90.8 \%$ in the registration of patients with all forms of IBD (from 11,040 in December 2007 to 21,066 in December 2014) (Fig. 1).

Following a sharp increase on the registration of cases from 2007 to 2010, we observe a tendency to a plateau from 2011, with a mean of $7 \%$ (variation, $6.5-8.0 \%$ ) of new cases of IBD registered yearly from 2011-2014
(Fig. 1). This information is crucial for policy planning, acquisition of FC and estimation of the number of patients who will need prophylaxis and might develop inhibitors, according to reported incidences.

As expected, the prevalence coefficient of $\mathrm{HA}$ e $\mathrm{HB}$ also changed as a reflection of the increment in registration. The prevalence coefficient of HA increased from $0.73 / 10,000$ in 2007 [6] to $1.00 / 10,000$ males in 2014 [14]. For HB, the coefficient was $0.48 / 35,000$ in 2007 [6] and 0.70/35,000 males in 2014 [14]. Differences between states remain, although less pronounced in 2014 when compared with 2007 (data not shown).

Historical data (2002-2014) on the relative distribution of the IBD showed a reduction in the percentage of HA and HB (in relation to all IBD) from 70.94 to $45.65 \%$ and 11.62 to $8.93 \%$, respectively and an increase in the percentage of $\mathrm{vWD}$ and other IBD from 11.36 to $31.06 \%$ and 2.65 to $14.36 \%$, respectively (Table 1 ). Rare bleeding disorders and platelet disorders account for the majority of the reported "other IBD" and their prevalence is detailed in Table 2.

\section{The impact of the system on clinical data of IBD}

In December 2014, most (62.6\%) patients registered with IBD are female (after excluding all PWH) and 39\% are in the age range of 20-39 years. In December 2014, severe, moderate and mild HA accounted for 38.3, 23.7 and $25.0 \%$ of patients, respectively. Severity was not informed in $13.0 \%$ of the patients, slightly lower than reported in 2007, $17.5 \%$ [6]. Severe, moderate and mild HB accounted for 31.4, 33.4 and 22.2\%, respectively. Similar to HA, severity was not informed in $12.9 \%$ of the patients, slightly lower than reported in 2007, 14.2\% [6].

In 2014, 77.8 and $79.0 \%$ of patients with $\mathrm{HA}$ and $\mathrm{HB}$, respectively, were tested for inhibitors (screening test), when compared with 2007, which were 58.6 and $59.7 \%$, respectively [6]. In 2014, 7.3\% $(n=698)$ and

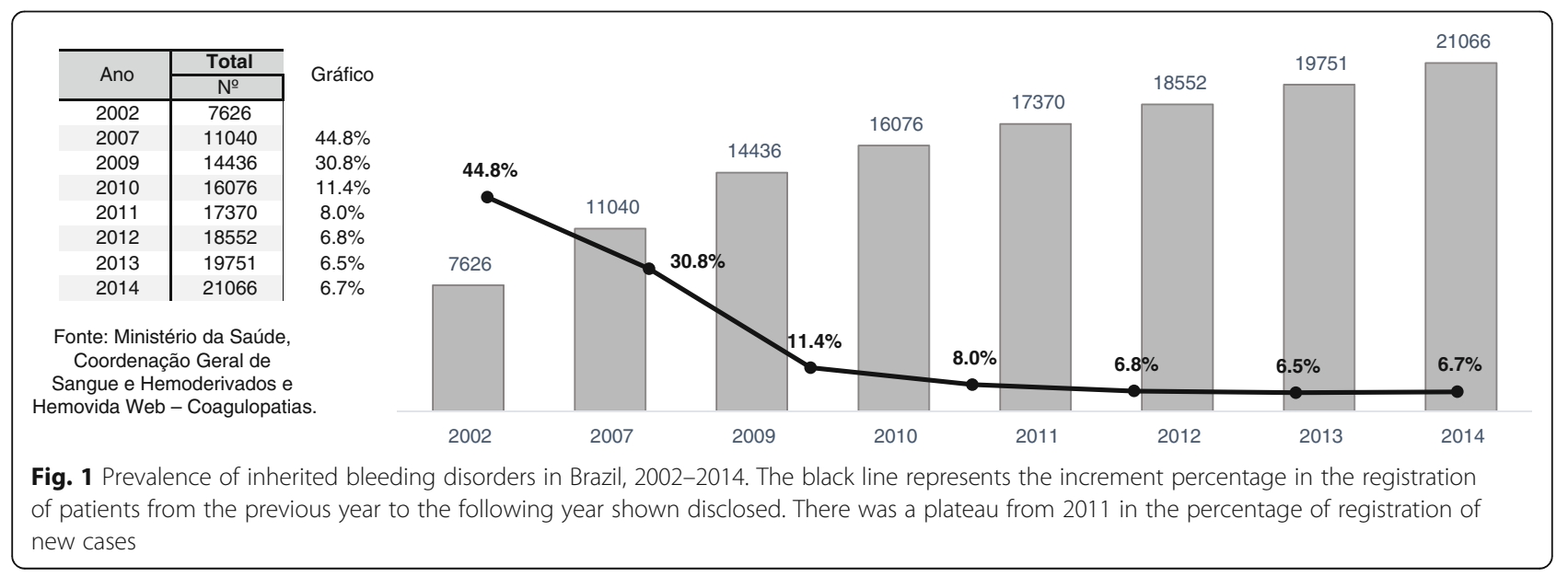


Table 1 Historical prevalence of inherited bleeding disorders, Brazil, 2002-2014

\begin{tabular}{|c|c|c|c|c|c|c|c|c|c|c|c|c|}
\hline \multirow[t]{2}{*}{ Year } & \multicolumn{2}{|c|}{ Haemophilia A } & \multicolumn{2}{|c|}{ Haemophilia B } & \multicolumn{2}{|c|}{ von Willebrand's disease } & \multicolumn{2}{|c|}{ Other inherited bleeding disorders ${ }^{a}$} & \multicolumn{2}{|c|}{ Not informed } & \multicolumn{2}{|l|}{ Total } \\
\hline & $\mathrm{N}$ & $\%$ & $\mathrm{~N}$ & $\mathrm{~N}$ & $\mathrm{~N}$ & $\%$ & $\mathrm{~N}$ & $\%$ & $\mathrm{~N}$ & $\%$ & $\mathrm{~N}$ & $\%$ \\
\hline 2002 & 5,411 & 70.95 & 886 & 11.62 & 866 & 11.36 & 202 & 2.65 & 261 & 3.42 & 7,626 & 100 \\
\hline 2007 & 6,881 & 62.33 & 1,291 & 11.69 & 2,333 & 21.13 & 316 & 2.86 & 219 & 1.98 & 11,040 & 100 \\
\hline 2009 & 7,905 & 54.76 & 1,516 & 10.50 & 3,822 & 26.48 & 1,015 & 7.03 & 178 & 1.23 & 14,436 & 100 \\
\hline 2010 & 8,369 & 52.06 & 1,609 & 10.01 & 4,451 & 27.69 & 1,437 & 8.94 & 210 & 1.31 & 16,076 & 100 \\
\hline 2011 & 8,848 & 50.94 & 1,723 & 9.92 & 4,934 & 28.41 & 1,865 & 10.74 & 0 & 0.00 & 17,370 & 100 \\
\hline 2012 & 9,122 & 49.17 & 1,801 & 9.71 & 5,445 & 29.35 & 2,184 & 11.77 & 0 & 0.00 & 18,552 & 100 \\
\hline 2013 & 9,348 & 47.33 & 1,838 & 9.31 & 5,976 & 30.26 & 2,589 & 13.11 & 0 & 0.00 & 19,751 & 100 \\
\hline 2014 & 9,616 & 45.65 & 1,881 & 8.93 & 6,544 & 31.06 & 3,025 & 14.36 & 0 & 0.00 & 21,066 & 100 \\
\hline
\end{tabular}

${ }^{a}$ This includes rare bleeding disorders, platelet disorders, hemophilia carriers and unknown bleeding disorders

$1.4 \%(n=27)$ of patients with $\mathrm{HA}$ and $\mathrm{HB}$, respectively, had a positive inhibitor screening test. Inhibitor titration was recorded in $77.4 \%(n=540)$ of patients with HA, who had a positive screening test $(n=698)$. Inhibitors were of low-response (less than $5 \mathrm{BU} / \mathrm{mL}$ ) in $43.7 \%(n=236)$ and of high-response $(>5 \mathrm{BU} / \mathrm{mL})$ in $54.4 \%(n=294)$ of patients with HA; in 10 patients (1.9\%) titration was negative. Inhibitor titration was recorded in $70.3 \%(n=19)$ of patients with $\mathrm{HB}$ who had a positive screening test $(n=27)$. Of these, $52.6 \%$ $(n=10)$ and $42.1 \% \quad(n=8)$ were low and high responders, respectively.

\section{The impact of the system on the assessment of factor concentrate use}

The use of FC and other procoagulants (such as desmopressin acetate and tranexamic acid) are routinely

Table 2 Prevalence of rare bleeding and platelet disorders

\begin{tabular}{lll}
\hline Rare bleeding and platelet disorders & $\mathrm{n}$ & $\%$ \\
\hline Afibrinogenemia & 35 & 1.6 \\
Hypofibrinogenemia & 40 & 2.1 \\
Dysfibrinogenemia & 11 & 0.5 \\
Factor II deficiency & 13 & 0.6 \\
Factor V deficiency & 157 & 7.7 \\
Combined factor V and VIII deficiency & 27 & 1.1 \\
Factor VII deficiency & 723 & 35.4 \\
Factor X deficiency & 88 & 4.3 \\
Factor XI deficiency & 165 & 8.1 \\
Factor XIII deficiency & 61 & 3.1 \\
Deficiency of vitamin K-dependent factors & 13 & 0.6 \\
Other combined deficiencies & 46 & 2.3 \\
Bernard Soulier syndrome & 59 & 2.9 \\
Glanzmann's trombastenia & 244 & 12.1 \\
Other platelet disorders & 359 & 17.6 \\
Total & 2,041 & 100 \\
\hline
\end{tabular}

recorded for all registered patients with IBD who receive treatment.

Regarding the categories of use of FVIII concentrate in 2014, secondary prophylaxis, home treatment, infusion in the HTC, ITI, hospital treatment and primary prophylaxis accounted for 49.9, 27.1,10.6, 8.0, 3.0 and 1.4\%, respectively. For FIX concentrate, secondary prophylaxis, home treatment, infusion in the HTC, hospital treatment and primary prophylaxis accounted for 43.2, 29.0, $20.0,6.8$ and $1.0 \%$ of use in 2014, respectively.

When all PWHA $(n=9,616)$ and all PWHB $(n=1,881)$ were considered, mean use of FVIII and FIX concentrates per patient was $60,901 \mathrm{IU}$ and $51,562 \mathrm{IU}$, respectively in 2014. However, 6,492/9,616 (67.5\%) PWHA used FVIII concentrate in 2014, accounting for a (real) mean use of 90,207 IU of FVIII concentrate per patient. For PWHB, 1,250/1,875 (66.7\%) used FIX concentrate in 2014, accounting for a (real) mean use of 77,343 IU per patient.

Furthermore, in 2014, 5.9, 24.1 and $65.2 \%$ of FVIII concentrate was used for the treatment of mild, moderate and severe PWHA, respectively. Patients with no information on the severity of HA used $4.8 \%$ of the totality of FVIII concentrate consumed in 2014. Regarding FIX concentrate, 8.1, 37.8 and $49.1 \%$ were used for the treatment of mild, moderate and severe PWHB, respectively. Patients with no information on the severity of HB used $5.0 \%$ of the totality of FIX concentrate consumed in 2014.

The increment of the purchase of FVIII and IX concentrates after 2010 in Brazil reflects the data on the per capita use of these products. In 2014, per capita use of FVIII and FIX in Brazil was 2.89 and 0.48 , respectively [14]. This represents an increment of 136.9 and $84.6 \%$ when compared with data from 2010, which were 1.22 and 0.26 , respectively [14]. Currently, 69.8 and $30.2 \%$ of PWHA are treated with recombinant and plasmaderived FVIII concentrate, respectively. The totality of PWHB are treated with plasma-derived FIX concentrate. 
The impact of the system on the implementation of prophylaxis and immune tolerance

Prophylaxis for severe and moderately-severe PWHA and PWHB ( $<2 \%$ of factor activity level) and ITI for PWHA and persistent inhibitors were implemented in Brazil in the end of 2011. Both programs were made available due to the provision of data on new cases of $\mathrm{HA}$ and $\mathrm{HB}$, haemophilia severity and inhibitor development from January 2009. Since the registration of new cases is performed via web, in real time, upon inclusion of the PWH in the system and information on severity, it is possible to identify PWH who will require long-term prophylaxis. Furthermore, by identifying new patients with inhibitors it is possible to include them on ITI at an early stage. By December 2015, we had 383 PWHA and PWHB on primary prophylaxis and 240 patients with hemophilia A on ITI.

Concerning ITI, the first phase of the program included patients with long-standing history of inhibitors, selected from the database according to the inclusion criteria. More recently, as there is more awareness about ITI program and inhibitor surveillance increased, patients who develop inhibitor have been included earlier in the course of this complication. Furthermore, the system allows for searching candidate patients, therefore promoting a more efficient action on the identification of patients with inhibitors who fill the criteria for ITI.

\section{Discussion}

The implementation of HWC, a web-based national registry had a major impact on the increment of the registration of patients with IBD, reflected by a rise of nearly $100 \%$ in the number of registered patients with all forms of IBD after 7 years of its onset. Furthermore, the system proved to be a good platform for the support of policy planning, promotion of health care, surveillance, allocation of resources and distribution of products.

According to the last published Annual Global Survey 2015 of the World Federation of Haemophilia (WFH), the total number of people with identified IBD in the world is 304,362 [15]. Within the 111 countries surveyed, Brazil has the fourth largest population of PWH $(n=11,857)$, after United States $(n=18,596)$, India $(n=16,635)$ and China $(13,624)$ and the third population of patients with vWD $(n=7,223)$ after United States $(n=13,845)$ and United Kingdom $(n=10,586)$ [15]. This position was been achieved after the implementation of HWC, which promoted a sharp rise in the registration of patients with IBD.

There was a sharp increment on the prevalence of IBD in Brazil from 2002-2014 until 2010. After 2011, there was a plateau in the registration of "new" patients with IBD reaching about $7.0 \%$ a year. Therefore, in the first 3 years after its implementation, HWC was an efficient tool in the promotion of the registration of patients with
IBD who were not already registered by the HTCs. However, since a major improvement in the diagnosis of these disorders occurred in Brazil in the same period, we cannot rule out the role of concurrent diagnostic strategies in the increment of the numbers registered.

The results here presented reflect patients' data collected from the totality of the HTCs in Brazil, which represent of most of the patients with IBD in the country. Although we do not have the precise numbers, a small proportion of patients with mild IBD are attended in private clinics and therefore might not be registered with the HTCs. However, once these patients require treatment, they are referred to the public HTCs and are then registered in the HWC.

HWC had an important impact on the management of patients with IBD, reflected by the collection of reliable data as well as acting as a platform to policy planning. By assessing the prevalence of IBD and the mean use of products per disease and severity it was possible to estimate required budget and amount of FC needed to treat patients. Information regarding the real-time registration of new patients with hemophilia, its severity and new patients with inhibitors also supported implementation of prophylaxis and ITI. Both initiatives were implemented according to data generated by HWC. Furthermore, the distribution of FC for the entire country as well as its use is now easily monitored by the stock control tool, which allows the control of distribution and use of FC from the central stock at the $\mathrm{MoH}$ to the patient.

There was a prompt adherence of HWC by health professionals in the HTCs. This was likely due to its simplicity of use, easily accessible web-based registry, "real-time" provision of data and feasibility to download, save and print reports of the patients, which facilitated the incorporation of relevant medical information into patients' files. Furthermore, we used a successful strategy for qualification and training of health professionals who worked with the system in the HTCs, which involved annual national meetings for discussion, presentation of data and innovations to the system. However, it is important to consider that part of the reason for a prompt adherence might be due to the compulsory need for registration of any patient with IBD who required use of any pro-coagulant product from January 2009.

HWC incorporated all the mandatory parameters recommended for the implementation of a national registry, such as personal and demographic, diagnosis and treatment details, bleeding history and serology $[11,16]$. Furthermore, most of the optional parameters were also included such as joint status, death and cause of death, vaccination status and genetic information [11].

HWC has aspects which need improvement, either related to the (i) inclusion of additional parameters or to (ii) qualification of data. Additional parameters should 
focus on data related to hospitalization, surgery, quality of life assessment and genetic information. Qualification of data is still an important issue in many registries [12]. In HWC, we noticed that some variables such as vaccination status, serology, clinical data (severity of disease, inhibitor status, follow-up visits) and treatment data (infusion charts, detail of prophylactic scheme and adherence) are targets to improvement. Information on death and mortality cause is hardly obtained by HTCs. Furthermore, the registry does not pursue an appropriate strategy for surveillance parameters known to be important in IBD, such as inhibitor, infectious diseases, infusion reactions nor a facility which allow patients themselves to insert infusion data in the system.

\section{Conclusions}

HWC, a national, web-based, real-time registry on IBD, had a major impact in the registration of IBD in Brazil in comparison with a manually-based national registry. Furthermore, its implementation promoted a prompt improvement on policy planning, which enhanced the quality of care of IBD in Brazil. We recommend all countries to implement national registries on IBD.

\section{Abbreviations}

FC: Factor concentrate; HA: Hemophilia A; HB: Hemophilia B;

HTC: Hemophilia treatment center; HWC: Hemovidaweb Coagulopatias; IBD: Inherited bleeding disorders; ITI: Immune tolerance induction; MoH: Ministry of health; PWHA: Patient with hemophilia A; PWHB: Patient with hemophilia B; SUS: Sistema Unico de Saude; VWD: von Willebrand disease; WFH: World federation of heophilia

\footnotetext{
Acknowledgements

*HEMOVIDAweb Coagulopatias Study Group is composed by: Anelisa Schittini Costa Streva (Centro de Hematologia e Hemoterapia da Bahia), Katty Pollyanni Ferreira Silveira (Centro de Hematologia e Hemoterapia de Alagoas), Sylvia Daniella Freitas de Souza (Centro de Hematologia e Hemoterapia de Sergipe), Sandra Sibele Leite Vieira de Figueiredo (Centro de Hematologia e Hemoterapia da Paraíba), Dario Itapary Nicolau (Centro de Hematologia e Hemoterapia do Maranhão), Irian Guedes Farkatt (Centro de Hematologia e Hemoterapia do Rio Grande do Norte), Ana Elzira Dantas Leopoldino Rocha (Centro de Hematologia e Hemoterapia do Piauí), ́ris Maciel Costa (Centro de Hematologia de Pernambuco), Rosângela de Albuquerque Ribeiro (Centro de Hematologia e Hemoterapia do Ceará), Maria do Carmo da Silva Assunção (Centro de Hemoterapia e Hematologia do Amazonas), Viviane Pereira de Moraes (Centro de Hemoterapia e Hematologia de Roraima), Ana Lice Sousa de Sena (Centro de Hemoterapia e Hematologia do Pará), Thereza Cristina Picado Pinheiro (Centro de Hemoterapia e Hematologia do Acre), Witânia Do Socorro Cardoso Silva (Centro de Hemoterapia e Hematologia do Amapá), Pollyana Gomes de Souza Pimenta (Centro de Hemoterapia e Hematologia de Tocantins), Juliana Camila Lopes Cavaion (Fundacao Hemocentro de Brasilia), Julimara Moreira Rocha Leonel de Paiva (Centro de Hemoterapia e Hematologia de Goiás), Dalva Gloria Ferreira França Barbacena (Centro de Hemoterapia e Hematologia de Mato Grosso), Sonia Maria Nunes De Barros (Centro de Hemoterapia e Hematologia do Rio de Janeiro), Maria do Perpétuo S. V. Orletti (Centro de Hemoterapia e Hematologia do Espírito Santo), Mitiko Murao (Centro de Hemoterapia e Hematologia de Minas Gerais), Luciene Figueiredo (Hemorrede de São Paulo), Liana Andrade Labres de Souza (Centro de Hemoterapia e Hematologia do Paraná), Denise Linhares Gerent (Centro de Hemoterapia e Hematologia de Santa Catarina), Giovana Fecker da Costa Diaz (Centro de Hemoterapia e Hematologia do Rio Grande do Sul), Jouse Fonseca Bittencourt (Centro de Hemoterapia e Hematologia de Mato Grosso do Sul), Walquíria Lima de Almeida (Fundação HEMERON).
}

\section{Funding}

This study had no funding.

\section{Availability of data and materials}

Data sharing is not applicable to this article.

\section{Authors' contributions}

SMR designed the research study; KNPB, DLQS, MLS, BJS, DAAB built the web-based system; SHLR and KNP analysed the data; GG, JPBA, HTM contributed essential tools; SMR, DAAB, SHLR, KNP wrote the paper. HWC Study Group participated on the collection of essential data. All authors revised the manuscript. We thank all staff from the haemophilia treatment centers who were involved with the collection of data. All authors read and approved the final manuscript.

\section{Competing interests}

The authors state that they have no competing interests which might be perceived as posing a conflict or bias.

\section{Consent for publication}

All authors gave their consent to submit and publish this manuscript.

Ethics approval and consent to participate

Ethical approval was waived for this study.

\section{Author details}

'Department of Internal Medicine, Faculty of Medicine, Universidade Federal de Minas Gerais, Avenida Alfredo Balena, 190 - 2nd floor- room 243, Belo Horizonte, Minas Gerais ZIP 30130-110, Brazil. ${ }^{2}$ Coordenação Geral de Sangue e Hemoderivados, Ministry of Health, SAF Sul, Edifício Premium, Torre II, room 202, CEP:70070-600 Brasília, Distrito Federal, Brazil. ${ }^{3}$ Departamento de Informática do Sistema Único de Saúde (DATASUS), Rua México - Centro, Rio de Janeiro ZIP 20031-143, Brazil. ${ }^{4}$ Hemocentro de Santa Catarina, Av. Othon Gama D'Eça, 756 Centro, Florianópolis, Santa Catarina ZIP 88015-240, Brazil. ${ }^{5}$ DVB Consultoria em Gestão em Saúde, Brasília, Distrito Federal, Brazil.

Received: 4 November 2016 Accepted: 22 December 2016 Published online: 10 February 2017

\section{References}

1. Dolan G, Makris M, Bolton-Maggs PH, Rowell JA. Enhancing haemophilia care through registries. Haemophilia. 2014;20 Suppl 4:121-9.

2. Ali T, Schved JF. Registry of hemophilia and other bleeding disorders in Syria. Haemophilia. 2012;18:851-4.

3. Aznar JA, Abad-Franch L, Cortina VR, Marco P. The national registry of haemophilia A and B in Spain: results from a census of patients. Haemophilia. 2009:15:1327-30.

4. Hassan HJ, Morfini M, Taruscio D, Abbonizio F, Giampaolo A, Kodra Y, Oliovecchio E, Vittozzi L. Current status of Italian registries on inherited bleeding disorders. Blood Transfus. 2014;12 Suppl 3:5576-81.

5. Pattacini C, Rivolta GF, Di Perna C, Riccardi F, Tagliaferri A. A web-based clinical record 'xl'Emofilia' for outpatients with haemophilia and allied disorders in the Region of Emilia-Romagna: features and pilot use. Haemophilia. 2009;15:150-8.

6. Rezende SM, Pinheiro K, Caram C, Genovez G, Barca D. Registry of inherited coagulopathies in Brazil: first report. Haemophilia. 2009;15:142-9.

7. Soucie JM, McAlister S, McClellan A, Oakley M, Su Y. The universal data collection surveillance system for rare bleeding disorders. Am J Prev Med. 2010;38:S475-81.

8. Von der Weid N. Haemophilia registry of the medical committee of the Swiss haemophilia society. Update and annual survey 2011/12. Hamostaseologie. 2013;33 Suppl 1:S10-4.

9. Walker I, Pai M, Akabutu J, Ritchie B, Growe G, Poon MC, Card R, Ali K, Israels $\mathrm{S}$, Teitel J, et al. The Canadian hemophilia registry as the basis for a national system for monitoring the use of factor concentrates. Transfusion. 1995;35: 548-51.

10. Zdziarska J, Chojnowski K, Klukowska A, Letowska M, Mital A, Musial J, Podolak-Dawidziak M, Windyga J, Ovesna P, Brabec P, Zawilska K. Registry of inherited bleeding disorders in Poland-current status and potential role of the HemoRec database. Haemophilia. 2011;17:e189-95. 
11. Alzoebie A, Belhani M, Eshghi P, Kupesiz AO, Ozelo M, Pompa MT, Potgieter J, Smith M. Establishing a harmonized haemophilia registry for countries with developing health care systems. Haemophilia. 2013; 19:668-73.

12. Keipert C, Hesse J, Haschberger B, Heiden M, Seitz R, van den Berg HM, Hilger $\mathrm{A}$. The growing number of hemophilia registries: quantity vs. quality. Clin Pharmacol Ther. 2015;97:492-501.

13. White 2nd GC, Rosendaal F, Aledort LM, Lusher JM, Rothschild C, Ingerslev J, Factor VIII and Factor IX Subcommittee. Definitions in hemophilia. Recommendation of the scientific subcommittee on factor VIII and factor IX of the scientific and standardization committee of the International Society on Thrombosis and Haemostasis. Thromb Haemost. 2001;85:560

14. Brito K, Rodrigues $S$, dos Santos A, de Lima L, Magalhães V, da Silva D, Rezende S. Perfil das Cogulopatias Hereditarias no Brasil. 2014.

15. Annual Global Survey 2015. World Federation of Hemophilia; 2016. pp. 68. http://www1.wfh.org/publications/files/pdf-1669.pdf.

16. Evatt B. Guide to Developing a National Patient Registry. World Federation of Hemophilia; 2005. http://www1.wfh.org/publication/files/pdf-1288.pdf. Accessed 1 Dec 2016.

Submit your next manuscript to BioMed Central and we will help you at every step:

- We accept pre-submission inquiries

- Our selector tool helps you to find the most relevant journal

- We provide round the clock customer support

- Convenient online submission

- Thorough peer review

- Inclusion in PubMed and all major indexing services

- Maximum visibility for your research

Submit your manuscript at www.biomedcentral.com/submit
Biomed Central 